\title{
Measurements of gas pressure in voids in epoxy castings for high voltage equipment
}

\section{Larsen, Esben; Henriksen, Mogens; Nielsen, E}

Published in:

IEEE International Symposium on Electrical Insulation. Conference Record

Link to article, DOI:

10.1109/ELINSL.1988.13944

Publication date:

1988

Document Version

Publisher's PDF, also known as Version of record

Link back to DTU Orbit

Citation (APA):

Larsen, E., Henriksen, M., \& Nielsen, E. (1988). Measurements of gas pressure in voids in epoxy castings for high voltage equipment. IEEE International Symposium on Electrical Insulation. Conference Record, 372-375. https://doi.org/10.1109/ELINSL.1988.13944

\section{General rights}

Copyright and moral rights for the publications made accessible in the public portal are retained by the authors and/or other copyright owners and it is a condition of accessing publications that users recognise and abide by the legal requirements associated with these rights.

- Users may download and print one copy of any publication from the public portal for the purpose of private study or research.

- You may not further distribute the material or use it for any profit-making activity or commercial gain

- You may freely distribute the URL identifying the publication in the public portal 
Measurements of Gas Pressure

in Voids in Epoxy Castings for

High Voltage Equipment

E. Larsen \& M. Henriksen, S.M. IEEE Electric Power Engineering Dept. Technical University of Denmark Bldg. 325, DK-2800 Lyngby DENMARK

\author{
E. Nielsen \\ ABLETRONIC \\ DK-2800 Lyngby \\ DENMARK
}

\section{Abstract}

This investigation deals with samples of epoxy each containing one void, which were produced at different pressures. The samples were of the disk type with the void located in the center.

Hence, by performing the curing at different pressures, it is assumed that the gas in the voids will have a pressure somewhat related to this curing-pressure, thereby having a direct influence on the partial discharge inception voltage.

In this paper are presented data which show that gas pressure in voids in epoxy castings can be determined by use of an ultrasound test method. It has also been found that in epoxy castings a relationship exists between void gas pressure and epoxy curing pressure.

This investigation shall be seen as part of an effort for exact prediction of the inception voltage for possible partial discharges in high voltage epoxy castings as a function of the processing parameters.

\section{INTRODUCTION}

For the measuring of the pressure in voids in epoxy castings, a rather new measuring principle has been introduced, called Time Delayed Spectrometry, based on that Fundamenta $\bar{l}$ fact that ultrasound travels at a finite, but different, velocity in the different media. This measuring technique, TDS, was first described by R.C. Heyser in 1967 , see Ref. 1 , and was at that time mainly used as an alternative to very expensive acoustical measurements in sound dead rooms, see Ref. 2 .

Some years ago the method was also applied for calibration (from $100 \mathrm{kHz}$ to $15 \mathrm{MHz}$ ) of special hydrophones in small water tanks, where the essentials of the applications are alike with regard to measurements in gases at low frequencies and in water at high frequencies.
From theoretical considerations of the ultrasonic damping of a signal travelling through water, epoxy, gas, again through epoxy and water, it can be calculated that the signal passing along the diagonal of a spherical void, $1 \mathrm{~mm}$ in diameter, will be attenuated as shown in Table $I$ below.

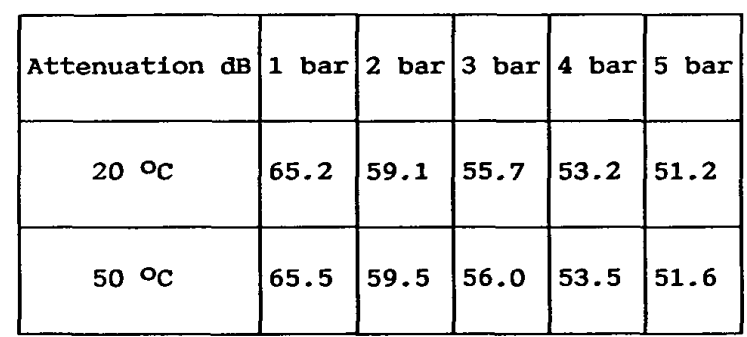

Table I.

From the numbers given in this table, it is clearly indicated that a relationship between the attenuation of the transmitted ultrasonic signal and void gas pressure exists - which, unfortunately, is also somewhat temperature dependent. This means that during tests this variable should be kept constant and, at the same time, recorded.

The basic test set-up that applies the above mentioned relationship, when used for void gas pressure measurements, therefore needs to include the following: An ultrasonic signal transmitter placed opposite a receiver, with the test sample containing the void to be tested placed in the direct path between the two, and all submersed in water.

The TDS measuring principle is then used to help to select a signal transmission path, which follows the direct path through the gas void, which is explained in more detail in Ref. 1 and 3 . 


\section{AND TEST PROCEDURES}

The apparatus used for the experiment here described is shown in the block diagram below, Figure 1 .

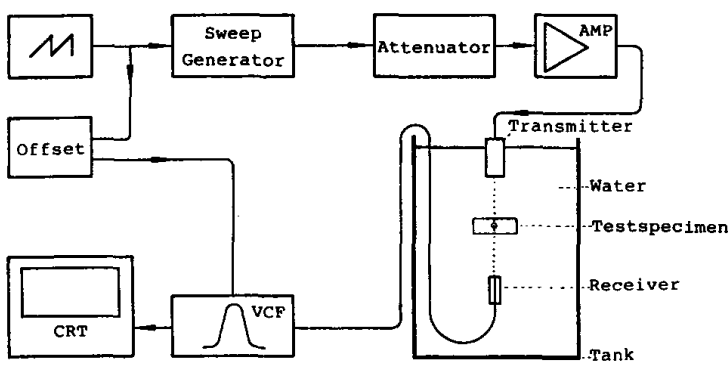

Figure 1

In general, the test method includes: A test signal, generated by a sweepgenerator, which is fed via an attenuator and an amplifier to the focusing transducer (transmitter). The frequency of the test signal increases at a constant, rate which is illustrated in Figure 2 .

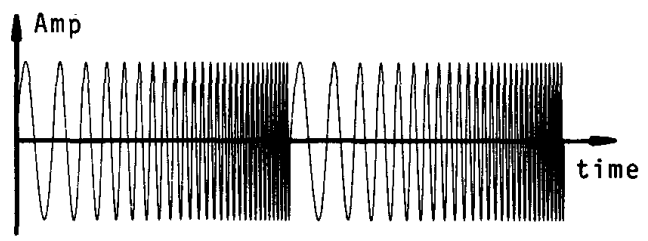

Figure 2.

The transmitter is a special transducer - Focused - based on a PZT-32 piezoelectric ceramic material (a modified lead titanate) with a focusing field of less than one millimeter, as ilustrated in Figure 3 .

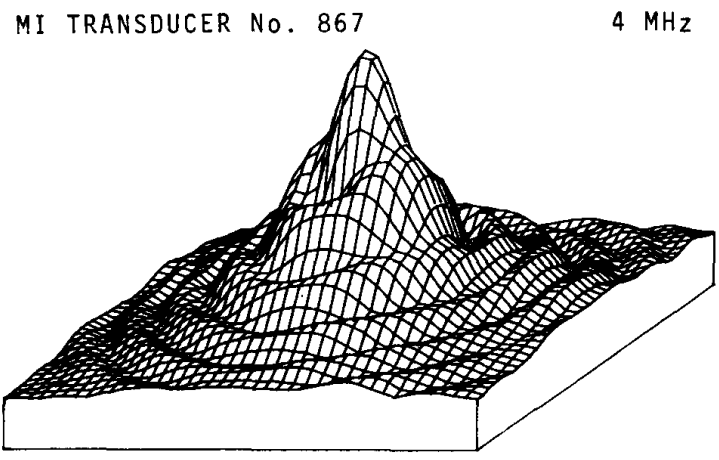

Figure 3.
The receiver is a needlelike hydrophone - PVDF (Polyvinylidene Fluoride) based, see Ref. 4 - with a linear characteristic from $1 \mathrm{MHz}$ to $15 \mathrm{MHz}$, see Figure 4 . By using such a hydrophone with a diameter of $1.0 \mathrm{~mm}$, the influence on the ultrasonic field is kept to a minimum, when at the same time, with a small active area a point wise reading is obtained.

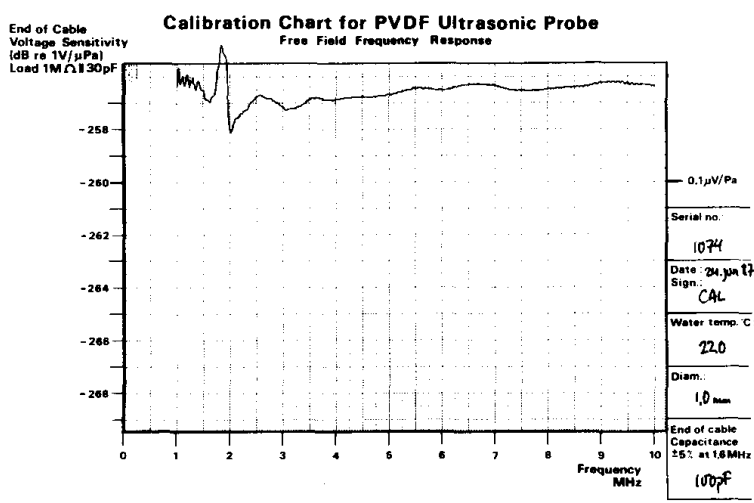

Figure 4.

The received signal at the hydrophone is fed to a spectrum analyzer via a variable filter, which normally consists of a fixed filter with an adjustable bandwidth and a mixer circuit.

Regarding the illustration of the test set-up shown in Figure 1, it should be added that more functions are included in each single "block" shown. A much more detailed description of this test set-up would be too extensive for this presenta-tion, but can be found in Ref. 1

\section{TEST PROCEDURE AND RESULTS}

Initial tests indicated that for this test purpose a frequency range from $100 \mathrm{kHz}$ to $8 \mathrm{MHz}$ could be used. It was also found that the maximum sensitivity of the system was obtained around $4 \mathrm{Mhz}$.

The liquid used in the test tank was distilled degassed water, in order to limit the attenuation of the test signal of this part of the test signal path.

The test specimens used for this test were all produced from the same epoxy resin system from Ciba-Geigy, CY-225\& HY-925 and the gas used to produce the void was clean, dry medical air. This production was performed at different pressures ranging from 1 bar-absolute to 5 bar-absolute. The pre-curing of the specimens was done at $80^{\circ} \mathrm{C}$ for 5 hours and the final cure at $135^{\circ} \mathrm{C}$ for 16 hours. 
In order to investigate the influence of the void diameter on the pressure recorded, two different void diameter ranges were used for the experiments, one with a diameter range from $1.01 \mathrm{~mm}$ to $1.09 \mathrm{~mm}$ and one from $2.18 \mathrm{~mm}$ to $2.34 \mathrm{~mm}$. The reason for choosing diameter ranges for this comparison was because the accuracy at which such voids can be produced is no better than $+/-0.2 \mathrm{~mm}$, unfortunately.

The thickness of all the epoxy test specimens was $5.0 \mathrm{~mm}(+/-0.1 \mathrm{~mm})$.

In order to obtain an optimum for the test set-up, first - without the test specimen an alignment-procedure of the "needle hydrophone" in respect to the transducer had to be performed with,

a) respect to the direct signal transmission path

b) and with respect to the focusing point of the transducer

in order to obtain maximum test signal, as shown in Figure 5.

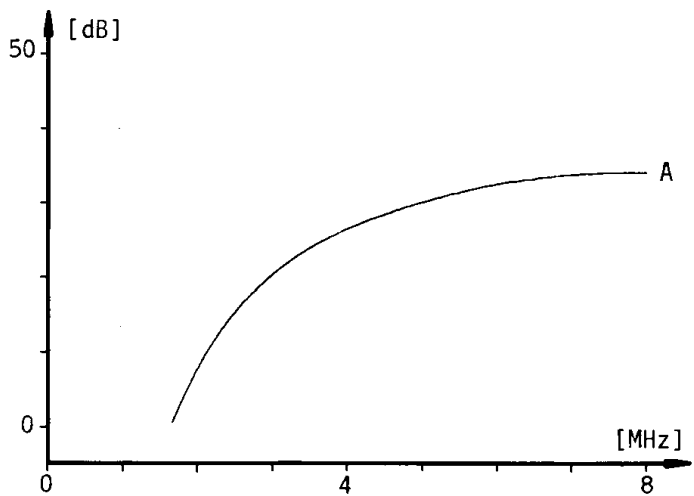

Figure 5

Temp.: $20^{\circ} \mathrm{C}$ Resolution Band width: $3 \mathrm{~Hz}$ Ref. Level: $-62.5 \mathrm{dBm}$

Then the test specimen was mounted and the above alignment-procedure (point b) was repeated. The results of such alignmentprocedures are shown in Curve $A$ on Figures 6,7 and 8 . Thereafter the gas void to be tested was brought into the direct signal transmission path leading to a reduction in the received test signal, as shown in Curve $B$ on Figures 6,7 and 8 . Finally the test signals were cleaned of all the reflections of the test signals by applying the TDS test technique, shown in Curve $C$ on Figures 6,7 and 8 , see also Ref. 3 and 4 .

In this last part of the test procedure is included an optimization of the test signal. When the tests are performed

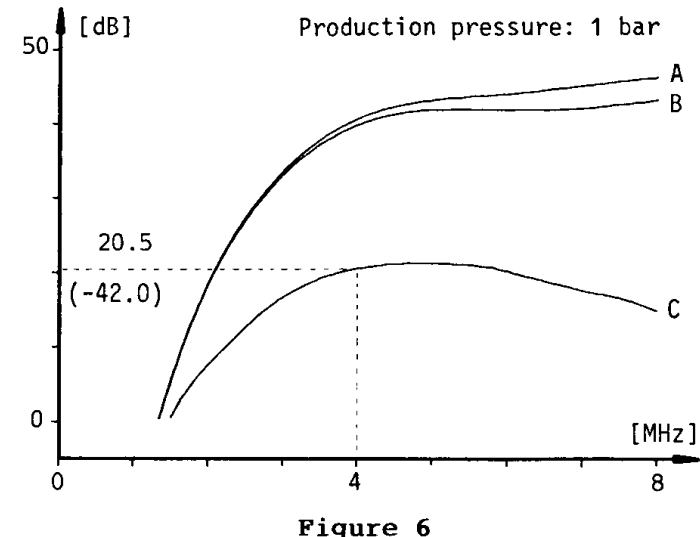

Temp. : $20^{\circ} \mathrm{C}$ Resolution Band width: $3 \mathrm{~Hz}$ Ref. Level: $-62.5 \mathrm{dBm}$ Optimizing Freq.: $4 \mathrm{MHz}$

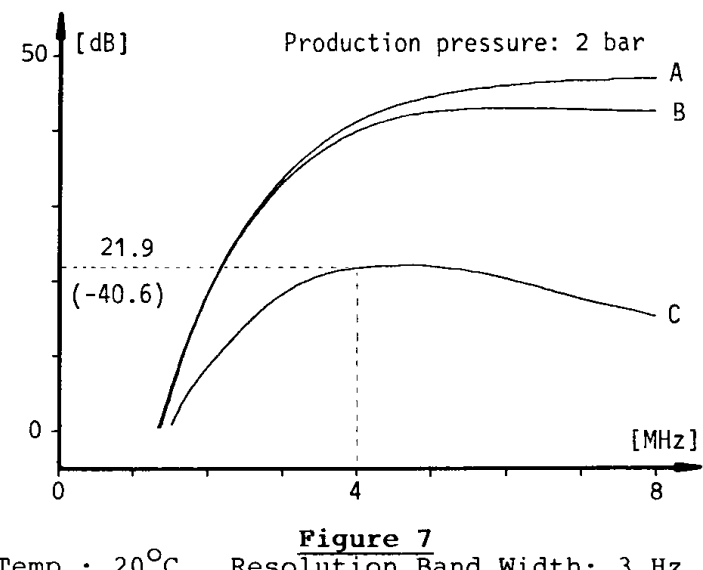

Ref. Level: $-62.5 \mathrm{dBm}$ Optimizing Freq.: $4 \mathrm{MHz}$

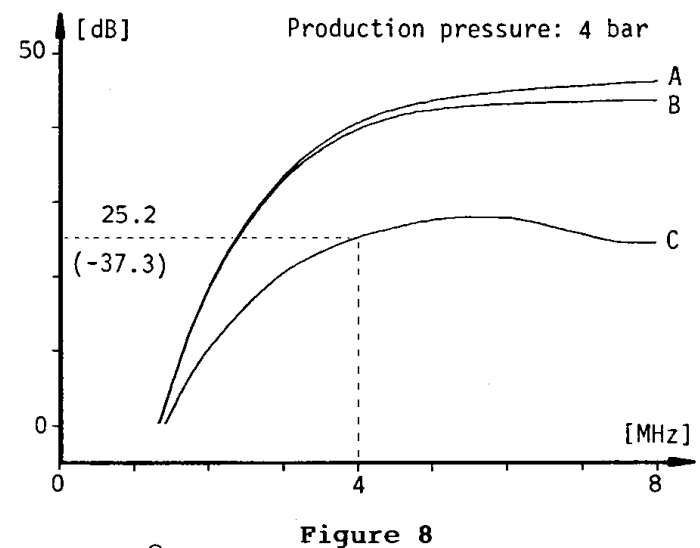

Temp.: $20^{\circ} \mathrm{C}$ Resolution Band wiath: $3 \mathrm{~Hz}$ Ref. Level: $-62.5 \mathrm{dBm}$ Optimizing Freq.: $4 \mathrm{MHz}$ 
manually, a specific optimizing frequency has to be chosen for this very important part of the test procedure, unfortunately. From the initial tests performed, it was found that a frequency of $4 \mathrm{MHz}$ would be a usable one, which is why this frequency has been used to obtain all the data presented in this paper.

In Figures 6,7 and 8 are shown the test results from samples in the void diameter range $1.01 \mathrm{~mm}$ to $1.09 \mathrm{~mm}$, and the values obtained at $4 \mathrm{MHz}$ are given.

The same kind of test curves, as shown in Figures 6,7 and 8 , were also recorded on samples in the void diameter range $2.18 \mathrm{~mm}$ to $2.34 \mathrm{~mm}$.

The test results on both diameter ranges at the $4 \mathrm{MHz}$, using the same input signal, are given in Table II.

\begin{tabular}{|c|c|}
\hline $\begin{array}{l}\text { Production pressure [ abar }] \\
\text { Vold diameter [man] }\end{array}$ & $\begin{array}{l}\text { Test signal measured } \\
\text { at 4 MHz [dBm] }\end{array}$ \\
\hline $1 / 1.04$ & -42.0 \\
$2 / 1.01$ & -40.6 \\
$4 / 1.09$ & -37.3 \\
\hline $1 / 2.27$ & -47.8 \\
$2 / 2.18$ & -44.5 \\
\hline
\end{tabular}

Table II.

\section{CONCLUSION}

The presented results show that in gas filled voids in an unfilled epoxy, the relative pressure can be determined by applying the TDS measuring technique in a special way.

When such gas filled voids are cured at different pressures, a relationship exists between the void gas pressure and the curing pressure - the higher the curing pressure, the higher the void gas pressure.
The test also has shown that such parameter as the void size has marked influence on the measured signal. This, to some extent, leads to the conclusion that when performing absolute pressure measurement tests, one has to compare the test results with results obtained on a model void in the same size-range where the pressure can be controlled and measured from the outside.

It can also be concluded that in order to obtain reliable and reproducible absolute pressure measurements, the applied TDS test method needs to be fully automated in order to apply a range of frequencies for the test signal optimization.

These results also show that the inception voltage for partial discharges in voids in epoxy castings is somewhat dependent on the method used for this production, i.e. pressure-gelation, vacuum/pressure- gelation or vacuum-gelation.

\section{Acknowledgements}

The authors wish to thank the Electric Power Research Institute for partly funding this work under contract RP2669-1.

\section{REFERENCES}

1. R.C. Heyser, "Acoustical Measurement by Time Delay Spectrometry", JAES, Vol. 15 , no. 4. 1967.

2. H. Biering \& 0.2 . Pedersen, "System Analysis and Time Delay spectrometry (Part II)", Brul and Kjær Technical Review, 1983

3. C.R. Cable \& J.K. Hilliard, "The Practical Application of Time-Delay spectrometry in the Field", JAES, vol. 28 , no. 5, 1980 .

4. P.A. Lewin, "Calibration and Performance of Miniatute Ultrasonic Hydrophones Using Time Delay Spectrometry", IEEE Ultrasonic Symp. Procee., pp. 660-664, 1981 . 